\title{
Ondjaki, um apanhador de memórias
}

\section{Flávia Cristina Bandeca Biazetto ${ }^{\mathrm{I}}$}

1 Flávia Cristina Bandeca Biazetto, doutora e mestre em Estudos Comparados de Literaturas de Língua Portuguesa (FFLCH /USP), graduada em Letras ( USP) e Jornalismo (Mackenzie). Atua como Ensino à distância na Univesp. 
Nascido em Luanda, em 1977, Ondjaki - pseudônimo de Ndalu de Almeida - encanta os leitores por sua sensibilidade em narrar. Suas histórias se apresentam em diferentes formatos: prosa, verso, teatro e documentário, e revelam sua versatilidade como artista. Com delicadeza, suas narrativas convidam a adentrar nos espaços sociais de Angola e a trilhar os caminhos da literatura de seu país e da herança cultural das tradições orais.

Licenciado em Sociologia, o escritor declarou em entrevista ao site União dos Escritores Angolanos ${ }^{2}$ que sua formação inicial deu-lhe instrumentos para "outra visão da realidade social”. Isso é notável em seus textos, que trazem questões sociológicas não só talhadas pela linguagem literária, mas também enviesadas por um tratamento que conflui a singularidade do olhar de quem testemunhou, ficcionalizou e analisou, simultaneamente, o fato narrado.

Seu percurso como um artista das palavras iniciou-se muito cedo, em 2000, quando publicou o livro de poemas actu sanguíneo, o qual recebeu menção honrosa do Prémio António Jacinto, no mesmo ano. Desde então, foram vários títulos traduzidos para francês, espanhol, italiano, alemão, inglês, sérvio, sueco, chinês, swahili e polaco, e premiados, com os mais recentes reconhecimentos sendo o Prémio FNLIJ 2013 "literatura em Língua Portuguesa", com A bicicleta que tinha bigodes [Brasil], Prémio José Saramago 2013 (Portugal), com Os transparentes, Prémio FNLIJ 2014 "Literatura em Língua Portuguesa", com Uma escuridão bonita [Pallas, Brasil, 2013] e Prémio Littérature-Monde [categoria de literatura não francesa], com Os transparentes [França, 2016]. Este ano, lançou sua última obra, há gente em casa (Ed. Caminho), marcando mais uma incursão pelos versos.

Nesta entrevista para Literartes concedida por email, Ondjaki ilumina pontos sobre seu trabalho de uma maneira poética, indicando não só uma facilidade de transitar entre recursos da poesia e da prosa, mas também aclarando a linha tênue que pode separar os gêneros literários. Suas perspectivas encantam ao dar um toque de singeleza nas imbricações das tradições, das memórias, da ficção, da língua que compõe sua obra.

2 Disponível em: https://www.ueangola.com/entrevistas/item/851-entrevista-a-ondjaki-a-capacidade-de-sobre- 


\section{O malinês Hampâté Bâ destaca o papel da memória dentro da tradição} oral, como um instrumento de transmissão de um legado cultural de um povo. Podemos pensar que suas histórias, permeadas por memórias, sobretudo aquelas que tematizam os anos 80 , podem ser lidas por esse prisma? Ou seja, são memórias angolanas ou memórias individuais do escritor?

Essa é uma pergunta delicada para ser colocada a mim, enquanto autor. $\mathrm{O}$ escritor, que eu saiba, é angolano. Portanto está englobado e misturado, neste caso, o cidadão no escritor. Eu penso que há muita ficção no acto de lembrar. Recontar é recriar, sim, mas é também viver a lembrança de um outro modo. Cada pessoa tem o direito à sua própria memória ficcionada, que eu creio que acontece quase sempre assim. Não sei se há memórias colectivas distintas das memórias individuais... Há estórias à solta no mundo, entre as paredes da noite e a brisa da memória.

2. A estética das narrativas orais tem suas particularidades e, também, desvelam uma outra visão de mundo entre visível e invisível. Em sua produção, sobretudo para crianças e jovens, o diálogo com a estruturas narrativas de tradição oral é explícito. Diante de novas formas contemporâneas de narrar, em sua opinião, por que as narrativas que representam as tradições orais ainda são fontes de encantamento mesmo para culturas mais letradas e urbanizadas?

De novo, não sei se essa distinção é tão demarcada. Toda a tradição, como algo que veio do passado, teve que ser repensada no mundo contemporâneo. O oral, o mais tradicional, vai encontrado espaço de contacto ou de fricção com a cultura urbana, académica, digamos. E se há espaço, e eu creio que sim, há, é porque aquilo que se viveu e que é contado pela tradição oral não são apenas 'coisas de narrar'; são coisas, humanas, que fazem parte da nossa essência. Que constroem a Humanidade todos os dias. A Humanidade renasce todos os dias, portanto. Através das vozes dos mais-velhos, do olhar das crianças e dos erros da maioria dos adultos. Será?... 
3. Daniel Munduruku, escritor brasileiro indígena, uma vez declarou que, para conhecer as literaturas de pessoas que viveram imersas nas tradições orais, seria necessário apresentar, previamente, suas culturas, com intuito de aclarar as diferenças não só culturais, mas também a cosmovisão. Você acha que tal afirmação é apropriada também para que leitores, como nós brasileiros, possamos entender melhor a produção literária angolana contemporânea? Se sim, o que seria interessante conhecer dos angolanos, ao ler suas obras?

Eu acho que entendo a afirmação do Daniel, um grande autor brasileiro e um ser humano dado a essas profundidades do olhar. Penso também que para receber a literatura angolana, ou outra, basta ter o coração e os olhos abertos, arejados. Não pensarmos tanto o que seria interessante conhecer 'dos angolanos', mas sim de 'um outro povo'. Claro que, se fizer sentido para o povo brasileiro, o que liga o povo brasileiro ao povo angolano tem aspectos de uma matriz antiga e profunda. Estará o Brasil aberto e interessado em conhecer tanto o passado quanto o presente de Angola? Só os brasileiros poderão responder.

4. Sua obra ficcional e poética propõe mudanças de percepção e de olhar do leitor para o mundo. Ela é uma obra política?

Quero pensar que é sobretudo uma tentativa modesta de fazer algum tipo de arte. Se um poema não propõe, no mínimo, alguma alteração na sensibilidade do leitor, de onde veio esse poema? E para onde quer o autor do poema que o mundo vá? A arte, digamos, em si, é política. Busca algum tipo de mudança. Nem que seja, pela manhã, quando o leitor termina o poema, um breve suspiro. Ou um outro modo de começar o dia. Ou uma nova maneira de enfrentar o seu mundo e o dos outros. Ou um caminho para uma nova indignação. Ou uma janela para um sonho inesperado. Algo assim. 
5. Em que país se concentra o maior número de seus leitores? Você considera esse leitor/interlocutor na elaboração de suas narrativas?

Não tenho esses dados. Poderia especular que será sobretudo o público de Portugal que me lê. Mas aí estaremos a falar de números. E leitores não são números, não para mim. São pessoas com olhares singulares e mãos que viram as páginas. São cúmplices, não dos meus livros, mas da vida geral deste planeta. O que eu considero é a arte da literatura na hora de escrever e de contar. O lugar da escrita emocional, o lugar da escrita que celebra a 'coisa contada', a 'coisa sonhada'. Como vê não tenho resposta para isso, estou só a inventar um novo pedaço de mundo.

6. Em sua obra, tanto a literária como o documentário "Oxalá cresçam pitangas", Luanda extrapola o papel de cenário. Ela é complexa e interage com os personagens, mostrando sua ligação íntima com sua cidade natal. Como viver tantos anos fora de seu país interferiu em sua relação com Luanda?

Eu já voltei para Angola. Já moro de novo em Luanda. Sei que a distância afecta, sim. Traz distância, saudade, um brilho mais difuso porque longínquo; uma noção distorcida, para melhor ou para menos melhor. Mas agora, para saber o que os anos fora 'me fizeram', eu tenho que esperar pelos novos anos 'dentro'. Estando em Luanda, para descobrir 'o que fazer' com essa bagagem emocional acumulada. Eu sou uma pessoa de espera. Estou à sempre espera. À espera de me reencontrar. À espera de reencontrar o sorriso da minha cidade. À espera de encontrar um personagem que pressinto mas que não chega. Neste exacto momento, por exemplo, estou à espera de saber como os anos que passei fora interferiram (ou não) na minha relação com Luanda... 


\section{Em entrevista a WOOK acontece, você destaca seu apreço por seus en- contros com as crianças. $\mathrm{O}$ que você leva para sua escrita desses encontros? O que gostaria que as crianças levassem deles?}

O que eu levo são os mais verdadeiros pedaços de vida. Alguns dos momentos mais felizes e puros da minha vida foram passados junto de crianças. De algum sorriso, de alguma frase absolutamente carregada de simplicidade. Talvez eu seja capaz de levar alguns ecos disso para a minha escrita, não sei. Nunca saberei. O que eu gostaria que as crianças levassem é um pouco do meu sonho e do meu amor. Se isso fizer sentido. Se isso for bom para elas. Na realidade há uma misteriosa ponte entre infância e velhice, que ainda está por ser explicada emocionalmente. Vejo isso como os extremos (da vida) que se tocam... O velho está sempre a preparar para reencontrar uma criança dentro de si. A criança aguarda que o velho brote e nasça dentro de si. No meio disso, veja bem, passa um tempo quase ridículo a que chamamos de 'vida adulta'. Mas, para mim, são esses dois extremos que concentram a intensidade da vida. Tanto a inocência quanto a aprendizagem. Tanto a intuição quanto a sabedoria. O meio do caminho, confesso, não me atrai tanto.

\section{O pequeno Ndalu costuma visitar o Ondjaki? Se sim, como são os reen- contros? Como interfere em sua escrita?}

$\mathrm{O}$ pequeno velho Ndalu anda com muita bagagem (quase no sentido de Adélia...). Às vezes chega, vem, devagar, e vem cansado, entregar bagagem a esse que se chama Ondjaki. E eu aqui com este corpo de anseios, desejos, medos, dores, costumes, amores, sonhares, a negociar essas entregas. Às vezes fico muito cansado. Por vezes choro, por vezes sorrio. Mas tento não interferir muito. Há algo de mais antigo e mais profundo que foge à minha compreensão lógica, e já aceitei isso. É mais importante, sobretudo, o 'contar'. Não interessa se é o escritor X ou Y. Interessa que conte. Que passe faça esse tráfico de conteúdos entre o passado inexplicável e o futuro por se desenhar. A minha escrita anda muito perto disso. E também dos 
olhos das crianças. E das mãos dos velhos. E dos restos das sombras das borboletas depois de pisarem a manhã. Ou não. Quem sabe? 